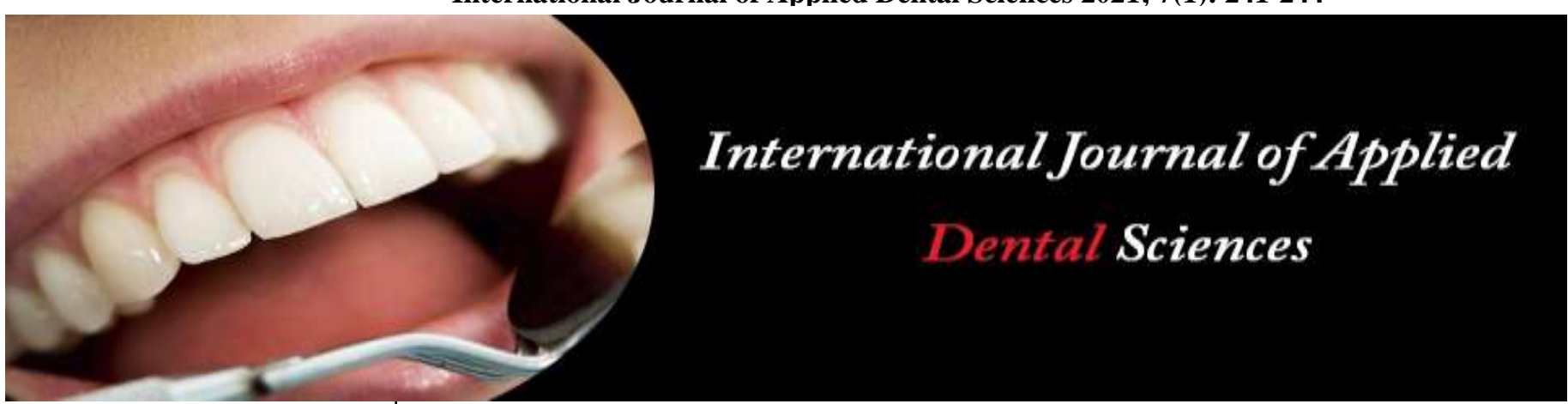

ISSN Print: 2394-7489

ISSN Online: 2394-7497

IJADS 2021; 7(1): 241-244

(C) 2021 IJADS

www.oraljournal.com

Received: 25-10-2020

Accepted: 05-12-2020

Dr. Sangavi Sithu Balakrishnan

Post Graduate Student,

Department of Conservative

Dentistry and Endodontics,

AJ Institute of Dental Sciences,

Mangalore, Karnataka, India

Dr. Swathi Amin

Reader, Department of

Conservative Dentistry and

Endodontics, AJ Institute of

Dental Sciences, Mangalore,

Karnataka, India

Dr. Rajaram Naik

Head of the Department,

Department of Conservative

Dentistry and Endodontics

AJ Institute of Dental Sciences,

Mangalore, Karnataka, India

\section{Influence of novel dry bonding approaches on the shear bond strength of a universal adhesive: An in vitro study}

\section{Dr. Sangavi Sithu Balakrishnan, Dr. Swathi Amin and Dr. Rajaram Naik}

DOI: $\underline{\text { https://doi.org/10.22271/oral.2021.v7.i1d.1139 }}$

\section{Abstract \\ Context:}

Aims: To determine the effect of novel dry bonding approaches on the shear bond strength of universal adhesive.

Settings and Design:

Methods and Material: The occlusal surface of forty extracted human molars were sectioned to expose the superficial dentin. The samples were randomly divided into four groups with 10 samples in each. The bonding to composite resin was done by a universal adhesive in the first group by self etch approach, second group by etch and rinse approach, the third and fourth groups were bonded by etch and rinse approach but additionally they were treated with Grape seed extract (GSE) and Dimethyl Sulfoxide (DMSO) prior to the application of the bonding agent according to the novel dry bonding approaches. Then, resin composite was inserted into a plastic tube placed on the specimen and light polymerized as per manufacturer's instructions. 5 samples in each group were stored in distilled water at $37^{\circ} \mathrm{C}$ for $24 \mathrm{hrs}$, the rest of the 5 samples in each group were thermocycled to mimic 1 year of aging. Then, shear bond strength analysis was done at a crosshead speed of $1.0 \mathrm{~mm} / \mathrm{min}$ in a universal testing machine. Finally, the mode of failure was analysed under a stereomicroscope.

Statistical analysis used: The statistical analysis for comparison of the mean bond strengths among the various groups was accomplished by Post-hoc Mann whiteney and Kruskal Wallis test.

Results: Thermocycling significantly reduced the bond strength in etch and rinse group. The highest bond strength at $24 \mathrm{hrs}$ and at one year was observed in DMSO treated group. Adhesive failure was seen more frequently in all the groups.

Conclusions: DMSO treated group showed significantly higher bond strength and bond durability.

Keywords: Dry bonding, grape seed extract, dimethyl sulfoxide, universal adhesive

\section{Introduction}

The revolution in many aspects of conservative dentistry has been brought about by adhesive dentistry by making possible the impossible clinical outcomes. The need for a retentive cavity has been eliminated by the current adhesive systems as they provide immediate bond strength while bonding to tooth structure. Two different strategies can presently be employed in resin bonding procedures: the etch-and-rinse technique (E\&R) and the self-etch (SE) or etch-anddry technique. The adhesives that can be used in both etch-and-rinse and self-etch strategies for bonding are called as the universal or multimode adhesives. Regardless of the strategy used, dentin bonding relies on the formation of the "hybrid layer" (HL), a structure composed of demineralized collagen fibrils reinforced by the resin matrix ${ }^{[1,2]}$. To form and maintain a tight adhesive resin-dentin interface that is stable for a number of years, providing retentive strength, marginal seal, and clinical durability are the major goals of adhesive procedures ${ }^{[3]}$.

Various strategies are being studied to reinforce the hybrid layer which include increasing the amount of resin penetration in the resin tag formation and enhancing the chemical bonding of adhesives to the hydroxyapatite crystals, amongst which collagen cross-linking agents show promising potential ${ }^{[4]}$. Proanthocyanidins (PA) have excellent cross-linking capability in addition to their anti-bacterial, anti-oxidant, anti-inflammatory, vasodilatory properties [5]. Grape Seed Extract (GSE), a proanthocyanidin, is a natural collagen cross-linker and its ability to crosslink dentin is comparable with glutaraldehyde ${ }^{[6]}$.
Dr. Sangavi Sithu Balakrishnan Post Graduate Student, Department of Conservative Dentistry and Endodontics, AJ Institute of Dental Sciences, Mangalore, Karnataka, India 
Bonding to the hard tissues is influenced by many factors, one of which is the solvent incorporated in the dental adhesive system. The monomer blends and dissolves in this solvent and is carried deep into the tooth structure to facilitate the proper infiltration of the exposed collagen network with the adhesive monomers ${ }^{[7,8]}$. Dimethyl sulfoxide (DMSO) is a polar aprotic solvent, which has ability to dissolve both polar and non-polar compounds. Additionally, DMSO is considered as one of the best penetration enhancers for studies. DMSO has been used to dissolve several dental monomers and components $[10,11]$ and in a concentration of $5 \%$ or higher it has an inhibitory effect on endogenous dentinal enzymes ${ }^{[4]}$.

These promising hybrid layer enhancers should be evaluated in terms of bond strength and bond durability which are the essential parameters influencing the clinical performance of an adhesive restoration. It is necessary to compare the properties of the novel bonding strategies to know if they can improve the quality of bonding beyond the currently followed bonding strategies.

The objective of the study is to evaluate.

1) The difference in the shear bond strength with DMSO and GSE treatment when compared to conventional etchand-rinse and self-etch bonding strategies.

2) The difference in the shear bond strength after thermocycling in these bonding strategies.

Thus, this study was conducted with an aim of evaluating the influence of novel dry bonding approaches using Grape seed extract (Proanthocyanidin) - a cross-linking agent and DMSO, a solvent on the shear bond strength of a universal adhesive.

\section{Subjects and Methods:}

Forty non-carious and non-restored human molars extracted for various clinical reasons were collected from private clinics, stored in $0.1 \%$ thymol solution for 2 weeks and then in distilled water at $4{ }^{\circ} \mathrm{C}$. All the teeth were used within 3 months from the time of extraction.

\section{Specimen preparation and bonding procedure}

The radiographs of the specimens were taken to locate the DEJ. The occlusal enamel, $1 \mathrm{~mm}$ below the DEJ of the molars was removed using a low-speed diamond saw under watercooling and grinded with 600 grit-size silicon-carbide papers for $15 \mathrm{~s}$ to create a standardized smear layer. Roots of the samples were embedded in self-cure acrylic resin.

The samples were randomly divided into 4 groups with ten samples in each group.

Group I: Universal bonding agent in self-etch

Group II: Universal bonding agent in etch-and-rinse mode

Group III: Universal bonding agent in etch and rinse dry bonding with GSE treatment

Group IV: Universal bonding agent in etch and rinse dry bonding with DMSO treatment

In the self-etch group (Group I), bonding was accomplished by application of two separate layers of solvated adhesive (3M ESPE Single Bond Universal adhesive, USA), followed by evaporation of the solvent for $5 \mathrm{~s}$ and light-curing for $40 \mathrm{~s}$ at $1200 \mathrm{~mW} / \mathrm{cm}^{2}$ using an 3M ESPE Elipar Deep cure light curing unit. Then, the composite resin (Coltene Brilliant NG, Switzerland) was condensed in a plastic mold of $4 \mathrm{~mm}$ diameter and $4 \mathrm{~mm}$ height in 3 increments of $1.5 \mathrm{~mm}$ each and cured individually for 20 s each ${ }^{[27]}$.

In the Etch and Rinse group (Group II), etching was done with $37 \%$ phosphoric acid (3M ESPE Scotchbond
Multipurpose Etchant, USA) for 15s and rinsed with water for 60 s and excess water was blotted using cotton rolls. Then, the bonding and composite resin build up was accomplished same as that followed in the self-etch group ${ }^{[27]}$.

In the GSE dry bonding group (Group III), etched and rinsed dentin was treated with GSE (Nature's Plus grape seed supplement with $95 \%$, Santa Cruz, CA, USA) for 60s, rinsed with water spray for 10 s and then air dried using full strength air from a 3 way syringe at a distance of $10 \mathrm{~cm}$ for $30 \mathrm{~s}$. Then bonded with Single bond plus adhesive and the composite resin build up was accomplished as mentioned above (Fig. 1, $2,3,4) .500 \mathrm{mg}$ of GSE was dissolved in $1 \mathrm{ml}$ of distilled water to get a 50\% GSE solution. Then, it was diluted with 10 $\mathrm{ml}$ of distilled water to obtain 5\% GSE solution ${ }^{[27]}$.

In the DMSO dry bonding group, etched and rinsed dentin was treated with 5\% DMSO (Central Drug House, P Ltd., India) for $30 \mathrm{~s}$, rinsed with water spray for $10 \mathrm{~s}$ and then air dried using full strength air from a 3 way syringe at a distance of $10 \mathrm{~cm}$ for $30 \mathrm{~s}$. Then bonded with Single bond plus adhesive adhesive and the composite resin build up was accomplished as mentioned above. The DMSO of $5 \%$ concentration was obtained by diluting the $97 \%$ DMSO with $19 \mathrm{ml}$ of distilled water ${ }^{[31]}$.

The groups were further subdivided with 5 samples in each by subjecting the samples to thermocycling. It is done to mimic the aging process for a period of 1 year.

Baseline group $\left(\mathrm{I}_{\mathrm{b}} \mathrm{II}_{\mathrm{b}} \mathrm{III}_{\mathrm{b}} \mathrm{IV}_{\mathrm{b}}\right)$ : stored at $37^{\circ} \mathrm{C}$ for $24 \mathrm{hrs}$.

Thermocycled group $\left(\mathrm{I}_{\mathrm{t}} \mathrm{II}_{\mathrm{t}} \mathrm{III}_{\mathrm{t}} \mathrm{IV}_{\mathrm{t}}\right)$ : at $5^{\circ} \mathrm{C}$ and $55{ }^{\circ} \mathrm{C}$ for 10,000 cycles after $24 \mathrm{hrs}$ in distilled water to allow the completion of polymerization reaction (Fig. 5)

Following thermocycling, all the samples were subjected to shear bond strength (SBS) test in a universal testing machine at a cross head speed of $1 \mathrm{~mm} / \mathrm{min}$. (Fig.5). Then the samples were studied under a stereomicroscope to observe the mode of failure (adhesive, cohesive or mixed failure).

\section{Statistical analysis}

The statistical analysis for comparison of the mean bond strengths among the various groups was accomplished by Post-hoc Mann whiteney and Kruskal Wallis test in SPSS version 20 with a significance level of $<0.05$.

\section{Results}

The shear bond strength of Group $\mathrm{I}_{\mathrm{b}}, \mathrm{II}_{\mathrm{b}}, \mathrm{III}_{\mathrm{b}}$ at $24 \mathrm{hrs}$ was not significantly different. The DMSO treated group $\mathrm{IV}_{\mathrm{b}}$ had the highest shear bond strength at $24 \mathrm{hrs}$.

It was observed that thermocycling significantly reduced the bond strength in the etch and rinse group (Group $\mathrm{II}_{\mathrm{t}}$ ). It did not influence the shear bond strength of the GSE treated group (Group $\mathrm{III}_{\mathrm{t}}$ ) and self-etch group (Group $\mathrm{I}_{\mathrm{t}}$ ). The DMSO treated group (Group $\mathrm{IV}_{\mathrm{b}}$ and Group $\mathrm{IV}_{\mathrm{t}}$ ) had the highest bond strength at $24 \mathrm{hrs}$ and also after one year though there was a significant fall in SBS after thermocycling.

Adhesive failure was seen more frequently in all the groups. Mixed failure was seen in one of the samples of $\mathrm{G} \mathrm{IV}_{\mathrm{b}}, \mathrm{G} \mathrm{III}_{\mathrm{t}}$. Cohesive failure was seen in one of the samples of $\mathrm{G} \mathrm{I}_{\mathrm{t}}$ (Fig. $9,10,11)$

\section{Discussion}

The durability of resin-dentin bond is limited. Hence, to improve the bond strength and durability many new formulations and compositions of dental adhesives are being devised. ${ }^{[12,13]}$ Shear Bond strength usually compares different formulations of adhesives and strategies of bonding. It gives a quantitative analysis of the bond strength. 
The mode of failure observed gives data on the quality of the bond between various interfaces. The occurrence of adhesive failure in a high proportion regardless of the strategy of bonding followed, signifies that the weakest zone is at the resin-dentin interface.

Evolution in adhesive dentistry has taken us from conventional dry bonding, wet bonding to self-etch (etch-anddry) and etch and rinse strategies. Recently, the concept of dentin dry bonding is studied extensively. It is carried out using various strategies - inhibition of enzymatic activity, cross-linking agents, removal of the unbound/residual water within the hybrid layer, calcium-chelation dry bonding, remineralisation of hybrid layer ${ }^{[14]}$.

In the etch and rinse strategy, 'wet bonding' has been proved to provide a greater bond strength than dry bonding. This is because of the residual water which prevents the collapse of the collagen meshwork ${ }^{[15,16]}$.

The universal adhesives have the capability to bind chemically to the inorganic hydroxyapatite in dentin. Hence, when universal adhesives are used in an etch and rinse strategy, concerns remain that demineralized dentin without resin impregnation may persist at the bottom of the hybrid layer, which will act as weaker region in the vicinity of the resin/dentin interface ${ }^{[17]}$. Thus, self-etching is preferred in dentin though the thickness of the hybrid layer formed is less but is better in quality when compared to that of etch and rinse technique. This led to the concept of Selective enamel etching (SEE). In this study, significant reduction in SBS is seen after thermocycling in etch and rinse group (Group $\mathrm{II}_{t}$ ) thereby indicating a poor quality of bond at the interface.

Dry bonding removes the residual water from the collagen meshwork and brings about the collapse of the meshwork thereby preventing the impregnation of the resin. This leads to a weaker resin-dentin inter-diffusion zone ${ }^{[27]}$.

Today, the removal of the unbound water from the hybrid layer and the silencing of the endogenous enzymatic activity are studied extensively using various chemical agents and physical approaches and are found to increase the effectiveness, biocompatibility and clinical applicability ${ }^{[14]}$.

Recent studies have shown increase in both immediate and long-term bond strength with DMSO treatment, a solvent used to remove unbound water from the hybrid layer ${ }^{[18,19,20]}$. One of the naturally occurring mechanism in dentin is the cross-linking of dentin matrix collagen and therefore, various chemical agents having cross-linking properties are being studied by researchers to enhance this mechanism. This causes bio-modification of the collagen scaffold enhancing the biomechanical properties of dentin, and making it less prone to proteolytic attack ${ }^{[21,22,23]}$.

Proanthocyanidins (PA) have excellent cross-linking capability equivalent to glutaraldehyde on dentin. It stiffens the collagen fibrils making them resistant to shrinkage and collapse on drying, thus allowing more resin penetration ${ }^{[21,24 \text {, }}$ 25, 26]. The dark brown color of GSE is the disadvantage as it cannot be used for adhesion in esthetic dentistry.

Zhou et al reported improved micro-tensile bond strength with GSE dry bonding for 60s, ${ }^{[27]}$ while Paulose et al. reported no significant improvement in the bond strength with GSE pretreatment ${ }^{[28]}$. This study does not show any significant difference in shear bond strength after GSE treatment. But the bond durability after thermocycling is comparable with the other groups. Though use of GSE in esthetic dentistry is questionable due to its limitations, it has shown to have a positive effect on bond durability as a crosslinking agent. Other clinically compatible cross-linking agents should be studied further on their potential to improve adhesion.

DMSO is an ideal solvent to facilitate radical polymerization reactions such as used in dental adhesion ${ }^{[10,11]}$. DMSO has the ability to breakdown the self-association ability of water molecules within dentin, disassociation of the tightly crosslinked collagen into a sparser network of fibrils. The increased spaces between the collagen meshwork may facilitate more consistent encapsulation of exposed collagen fibrils with the adhesive resin and reduction of exposed collagen at the base of the hybrid layer ${ }^{[20,29,30]}$.

In this study, DMSO treated teeth exhibited significant increase in shear bond strength. Similar to observations by Stape et al. ${ }^{[18,19]}$ Thus, DMSO has proven to be a promising agent to improve the quality and quantity of the resin adhesion.

The limitations of the study is, since it was done in vitro, the behavior of the agents under the influence of various clinical conditions were not studied. To standardize the study, only one type of universal adhesive and composite resin were used as these agents influence the bond at the adhesive resin-dentin interface and have insignificant action on the adhesive resincomposite interface.

Table 1: Specimen groups

\begin{tabular}{|c|c|c|c|c|}
\hline Group I (Self-etch) & Group II (Etch and Rinse) & Group III (GSE) & Group IV (DMSO) & \\
\hline${\text { Group } I_{b}}_{\text {Group } I_{t}}$ & Group II $_{b}$ & Group III $_{b}$ & Group IV $_{b}$ & $n=20$ \\
\hline $\mathrm{n}=10$ & Group II $_{t}$ & Group III & Group IV $_{t}$ & $n=20$ \\
\hline & $\mathrm{n}=10$ & $\mathrm{n}=10$ & $\mathrm{n}=10$ & \\
\hline
\end{tabular}

Table 2: Mean shear bond strength of various bonding strategies (*indicates statistically significant observation)

\begin{tabular}{|c|c|c|c|}
\hline Groups & Mean SBS (MPa) & Standard deviation (SD) & P value \\
\hline Group $\mathrm{I}_{\mathrm{b}}$ & 30.35 & 4.19 & 0.01 \\
\hline Group II & 30.45 & 4.23 & \\
\hline Group $\mathrm{III}_{\mathrm{b}}$ & 31.02 & 3.13 & \multirow{2}{*}{0.01} \\
\hline Group $\mathrm{IV}_{\mathrm{b}}$ & $35.56^{*}$ & 2.56 & \\
\hline Group $\mathrm{I}_{\mathrm{t}}$ & 28.47 & 4.56 & \\
\hline Group $\mathrm{II}_{\mathrm{t}}$ & $26.32^{*}$ & 2.86 & \\
\hline Group $\mathrm{III}_{\mathrm{t}}$ & 30.42 & 3.17 & \\
\hline Group $\mathrm{IV}_{\mathrm{t}}$ & $32.42^{*}$ & 2.29 & \\
\hline
\end{tabular}

\section{References}

1. Nakabayashi N, Nakamura M, Yasuda N. Hybrid layer as adentin-bonding mechanism. J Esthet Dent 1991;3:133-8.
2. Nakabayashi $\mathrm{N}$. The hybrid layer: a resin-dentin composite. Proc Finn Dent Soc 1992;88(Suppl. 1):321-9.

3. Tjäderhane L. Dentin bonding: can we make it last? 
OperDent 2015;40:4-18, http://dx.doi.org/10.2341/14095-BL.

4. Tjaderhane L, Nascimento FD, Breschi L, et al. Strategies to prevent hydrolytic degradation of the hybrid layer - a review. Dent Mater 2013;29:999-1011.

5. Kalra M, Iqbal K, Nitisusanta Li, et al. The effect of proanthocyanidins on the bond strength and durability of resin sealer to root dentine. Int Endod J 2013;46:169-178.

6. Macedo GV, Yamauchi M, Bedran-Russo AK. Effects of Chemical cross-linkers on caries-affected dentin bonding. J Dent Res 2009;88:1096-1100.

7. Pashley DH, Tay FR, Carvalho RM, Rueggeberg F, Agee K, Carrilho M, Donnelly A, García-Godoy F. From dry bonding to water-wet bonding to ethanol-wet bonding. A review of the interaction between dentin matrix and solvated resins using a macromodel of the hybrid layer. Am J Dent 2007;20:7-20.

8. Ekambaram M, Yiu CKY, Matinlinna JP. An overview of solvents in resin-dentin bonding. Int $\mathbf{J}$ Adhes Adhes 2015;57:22-33.

9. Marren K. Dimethyl sulfoxide: an effective penetration enhancer for topical administration of NSAIDs. Phys Sportsmed 2011;39:75-82.

10. Geurtsen W, Lehmann F, Spahl W, Leyhausen G. Cytotoxicity of 35 dental resin composite monomers/additives in permanent 3T3 and three human primary fibroblast cultures. J Biomed Mater Res 1998;41:474-480.

11. Thonemann B, Schmalz G, Hiller KA, Schweikl H. Responses of L929 mouse fibroblasts, primary and immortalized bovine dental papilla-derived cell lines to dental resin components. Dent Mater 2002;18:318-323.

12. Reis A, Loguercio AD, Carvalho RM, Grande RHM Durability of resin dentin interfaces: effects of surface moisture and adhesive solvent component. Dent Mater 2004;20:669-676.

13. Van Landuyt KL, Snauwaert J, De Munck J, Peumans M, Yoshida Y, Poitevin A, Coutinho E, Suzuki K, Lambrechts P, Van Meerbeek B. Systematic review of the chemical composition of contemporary dental adhesives. Biomaterials 2007;28:3757-3785.

14. Breschi L, Maravic T, Cunha SR, Comba A, Cadenaro M, Tjäderhane L, Pashley DH, Tay FR, Mazzoni A. Dentin bonding systems: from dentin collagen structure to bond preservation and clinical applications. Dent Mater 2018;34(1):78-96.

15. Brackett MG, Li N, Brackett WW, Sword RJ, Qi YP, Niu $\mathrm{LN}$, et al. The critical barrier to progress in dentine bonding withthe etch-and-rinse technique. J Dent 2011;39:238-48.

16. Abedin F, Ye Q, Parthasarathy R, Misra A, Spencer P. Polymerization behavior of hydrophilic-rich phase of dentinadhesive. J Dent Res 2015;94:500-7.

17. Moritake $\mathrm{N}$, Takamizawa $\mathrm{T}$, Ishii $\mathrm{R}$, Tsujimoto $\mathrm{A}$, Barkmeier WW, Latta MA, Miyazaki M. Effect of active application on bond durability of universal adhesives. Opr Dent 2019;44(2):188-99.

18. Stape THS, Tjäderhane L, Tezvergil-Mutluay A, Yanikian CRF, Szesz AL, Loguercio AD, Martins LR. Dentin bond optimization using the dimethyl sulfoxidewet bonding strategy: A 2-year in vitro study. Dent Mater 2016;32:1472-1481.

19. Stape THS, Tezvergil-Mutluay A, Mutluay MM, Martins LRM, do Prado RL, Pizi ECG, Tjäderhane L. Influence of dimethyl sulfoxide used as a solvent on the physical properties and long-term dentin bonding of hydrophilic resins. J Mech Behav Biomed Mater 2016;64:220-228.

20. Stape THS, Tjäderhane L, Marques MR, Aguiar FHB, Martins LRM. Effect of dimethyl sulfoxide wet-bonding technique on hybrid layer quality and dentin bond strength. Dent Mater 2015;31:676-683.

21. Bedran-Russo AKB, Pashley DH, Agee K, Drummond JL, Miescke KJ. Changes in stiffness of demineralized dentinfollowing application of collagen crosslinkers. J BiomedMater Res B Appl Biomater 2008;86:330-4, http://dx.doi.org/10.1002/jbm.b.31022.

22. $\mathrm{Xu} \mathrm{C}$, Wang $\mathrm{Y}$. Cross-linked demineralized dentinmaintains its mechanical stability when challenged bybacterial collagenase. J Biomed Mater Res B Appl Biomater 2011;96B:242-8, http://dx.doi.org/10.1002/j bm.b.31759.

23. Bedran-Russo AK, Pauli GF, Chen SN, McAlpine J, Castellan CS, Phansalkar RS et al. Dentin biomodification: strategies, renewable resources and clinical applications. Dent Mater 2014;30:62-76, http://dx.doi.org/10.1016/j.dental.2013.10.012.

24. Bedran-Russo AK, Castellan CS, Shinohara MS, Hassan L, Antunes A. Characterization of biomodified dentin matricesfor potential preventive and reparative therapies. ActaBiomater 2011;7:1735-41.

25. Liu Y, Dusevich V, Wang Y. Proanthocyanidins rapidly stabilize the demineralized dentin layer. J Dent Res 2013;92:746-52.

26. Liu Y, Dusevich V, Wang Y. Addition of grape seed extractrenders phosphoric acid a collagen-stabilizing etchant. J Dent Res 2014;93:821-7.

27. Zhou J, Chiba A, Scheffel DL, Hebling J, Agee K, Tagami J et al. Cross-linked dry bonding: A new etchand-rinse technique. Dent Mater 2016;32(9):1124-32.

28. Paulose NE, Fawzy AS. Effect of grape seed extract on the bond strength and durability of resin-dentin interface. J Adhes Sci Tech 2017;31(23):2525-41.

29. Tjäderhane L, Mehtälä P, Scaffa P, Vidal C, Pääkkönen $\mathrm{V}$, Breschi L et al. The effect of dimethyl sulfoxide (DMSO) on dentin bonding and nanoleakage of etch-andrinse adhesives. Dent Mater 2013;29:1055-1062.

30. Mehtälä P, Pashley DH, Tjäderhane L. Effect of dimethyl sulfoxide on dentin collagen. Dent Mater 2017;33:915922.

31. Al-Ani AA, Mutluay M, Stape TH, TJÄDERHANE L, Tezvergil-Mutluay A. Effect of various dimethyl sulfoxide concentrations on the durability of dentin bonding and hybrid layer quality. Dent Mater J 2018;37(3):501-5. 